\title{
Hereditary Contractures of the Fingers (Camptodactyly)
}

\author{
J. PHILIP WELCH and SAMIA A. TEMTAMY \\ From the Division of Medical Genetics, Department of Medicine, fohns Hopkins Hospital and fohns Hopkins Universit \\ School of Medicine, Baltimore, Maryland, U.S.A.
}

The occurrence of congenital contractures of the fingers, with apparent distinctions from the classic Dupuytren's contracture, has been recognized for well over a hundred years (Tamplin, I846). Despite a considerable volume of early work on the subject, particularly around the turn of the century, the condition seems to have been ignored and gradually forgotten, so that it now does not receive mention in most texts of general surgery, and Barsky (1958) does not include it in his standard text on the hand. Boyes (1964) and Souttar and Goligher (1958) make passing reference to its occurrence and Hamilton Bailey (1960) has a photograph of a case. Stern (1957) discussed the possibility of holandric inheritance in this condition, though many early papers (see Table) testify to a fairly clear-cut dominant pattern of inheritance.

The condition is characterized by a limitation of extension at the proximal interphalangeal joint, without limitation of flexion, typically accompanied by hyperextension at the metacarpophalangeal joint, and sometimes at the terminal interphalangeal joint. The little finger is the most frequently affected though any finger may be involved (usually in addition to involvement of the little finger); contracture bands may frequently be felt beneath the skin on the volar surface of the affected joint and the transverse skin creases in this location are invariably lost. The thumb and other finger joints rarely if ever show contractures. When the condition is bilateral, the hands usually show similar degrees of involvement. While the condition may be present at birth, it seems likely that it may often arise in early childhood. Progression is usually slight and occurs only during the first two decades; incapacity is also slight, largely due to the 'compensatory' hyperextension

Received September 13, 1965. at other joints. Some authors (Schaff and Schafe 1948) have reported an associated difficulty of abduction and adduction, but this is probably \& mechanical result of flexion at the proximal intero phalangeal joint.

It seems likely that the condition is not excessively rare but is frequently unrecognized, or classifie either as Dupuytren's contracture or as an old teno-synovitis.

Present interest in this condition was generated by its chance finding in the proband (J.M., JHI 496766) during examination for a probably uns related condition, essential hypertension. The clinical findings in the proband's family, and if certain other cases we have subsequently seer? are presented, and the published reports are reviewed in an attempt to renew awareness of the condition and of other anomalies with which it may be associated, and to make some suggestions regarding its relationship to Dupuytren's contraceture.

\section{Present Investigation}

The affected members of the family are as noted in the pedigree (Fig. I). Each stated that he hag had the condition as long as he could remembers and that there had been no progression.

The affected fingers were as described abovan and it may be stressed that flexion within the limited range was quite normal. (This provides $\mathbb{0}$ point of differentiation from an old teno-synovitise, There is thus no fusion of the joint, as a cursory inspection of an antero-posterior radiograph miger suggest and as has been proposed by others (Scharf and Schafer, 1948). The degree of limitation \& flexion is unaffected by the position of the wristr indicating that the impairment is not due shortening of the long flexor tendons as has beed suggested (Davis and Finesilver, 1932) and 


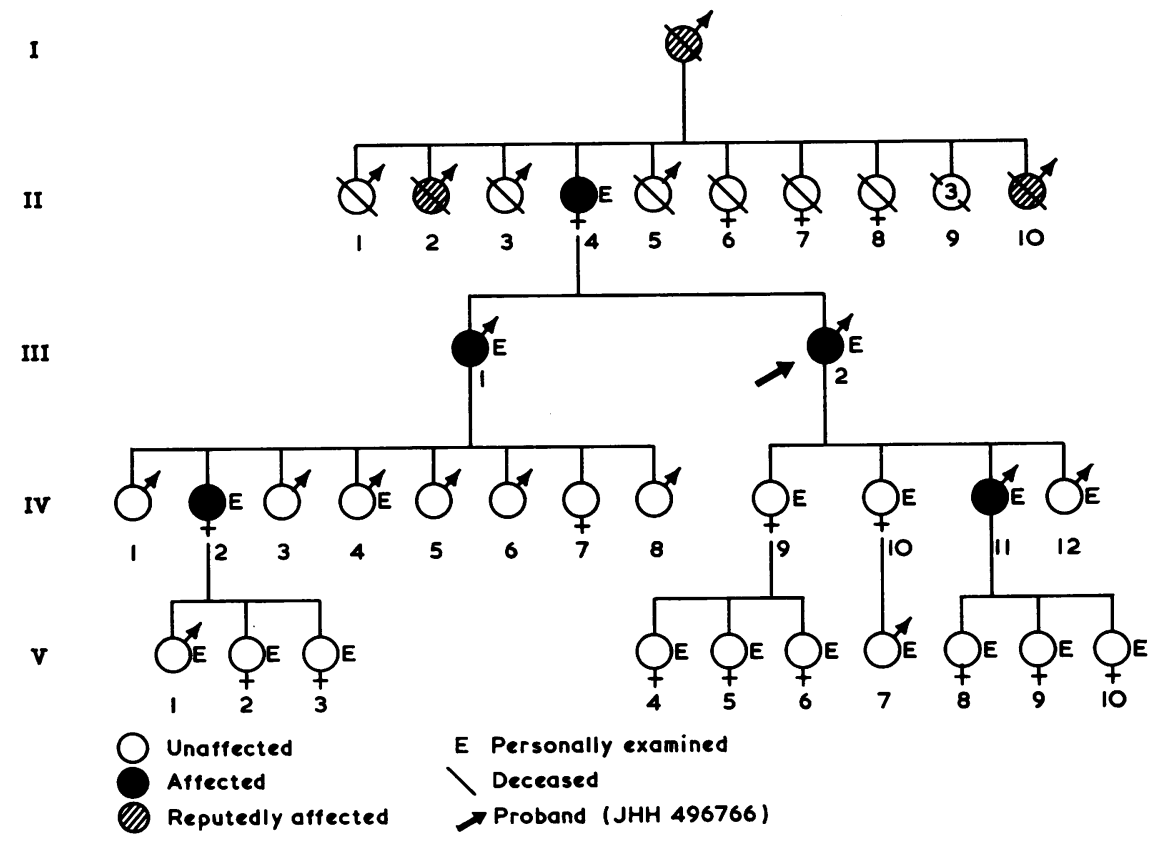

FIG. I.

is sometimes given as a point of differentiation from Dupuytren's contracture.

As other authors have remarked, the impression is of a 'tightness' of the volar skin and underlying tissue over the affected joint. Any contracture bands must be firmly adherent to the overlying skin, though there is no puckering of the skin nor are there any palpable bands, skin nodules, etc. in the palms of any case in this family. Only the proximal interphalangeal joint was affected, the feet were clinically normal in the case of all those examined, and there was no family history of any other joint disability or of epilepsy. No members of this family showed pectus excavatum, scoliosis, ptosis, or hypogonadism.

\section{Case Reports}

II.4: mother of the proband, aged 82, had all four fingers of the right hand affected, also the left middle and ring fingers. The middle finger of right hand was the most affected, extension being limited to $135^{\circ}$ (see Fig. 2). 'Knuckle pads' were present over the dorsal surface of the proximal interphalangeal joints of both index fingers.

III.I: brother of the proband, aged 64, had only fifth fingers affected bilaterally, with no knuckle pads.

III.2: proband, aged 62, had limitation of extension at proximal interphalangeal joints of all fingers except right and left index. The right hand was more affected than the left. On the right, the ring and fifth fingers were most affected, extension being limited to $140-145^{\circ}$. There were knuckle pads over the proximal interphalangeal joint on both index fingers, also on the middle fingers and the right ring finger (see Fig. 3). Radiographs of the hands did not show any bony abnormality; in particular the heads of the proximal phalanges appeared normal. Radiographs of the feet showed no abnormality.

IV.2: niece of the proband, aged 32, had only right fifth finger affected.

IV.II: son of the proband, aged 32, had fifth and ring fingers affected bilaterally and had no knuckle pads.

\section{Discussion}

Nomenclature. Most of the early references refer to the condition simply as congenital contractures of the fingers (Tamplin, 1846; Neuhof and Oppenheimer, I914; Forrester-Brown, 1929) or as congenital Dupuytren's contracture (Keen, 1882; Greig, 1917). It may be noted that contractures mentioned by Dupuytren (1854) in two young girls (one aged 4) and a r4-year-old boy, were probably cases of camptodactyly, and were apparently recognized by Dupuytren as a distinct entity, though attributed by him to 'deformity 


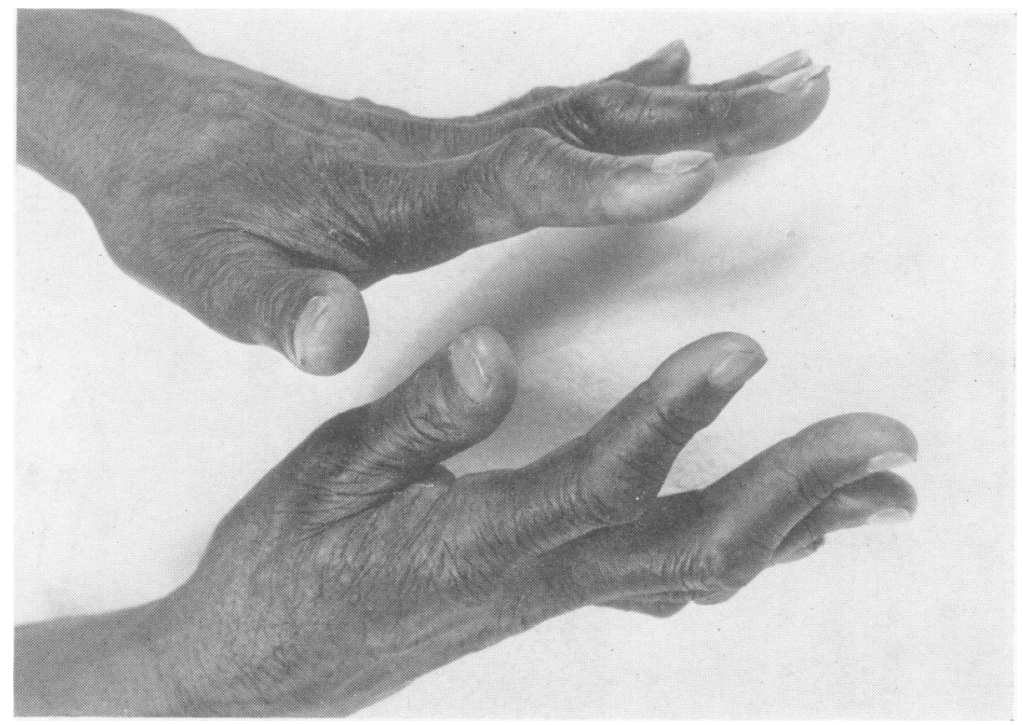

FIG. 2. Hands of II.4. Note the characteristic hyperextension at the metacarpophalangeal joints.

of the articulations'. Dupuytren also reported the occurrence of familial contractures of the toes (see 'hammer toes' below).

In 1885 Landouzy introduced the term 'camptodactylie' or camptodactyly (Lucas-Championnière,
1885). Subsequently, various descriptive terms have been applied such as 'flexed fingers' (Spear, 1940) and 'hammer fingers' (Whitman, 1930), and i. 1929, Hefner, describing a family in which on the fifth fingers were involved, coined the term

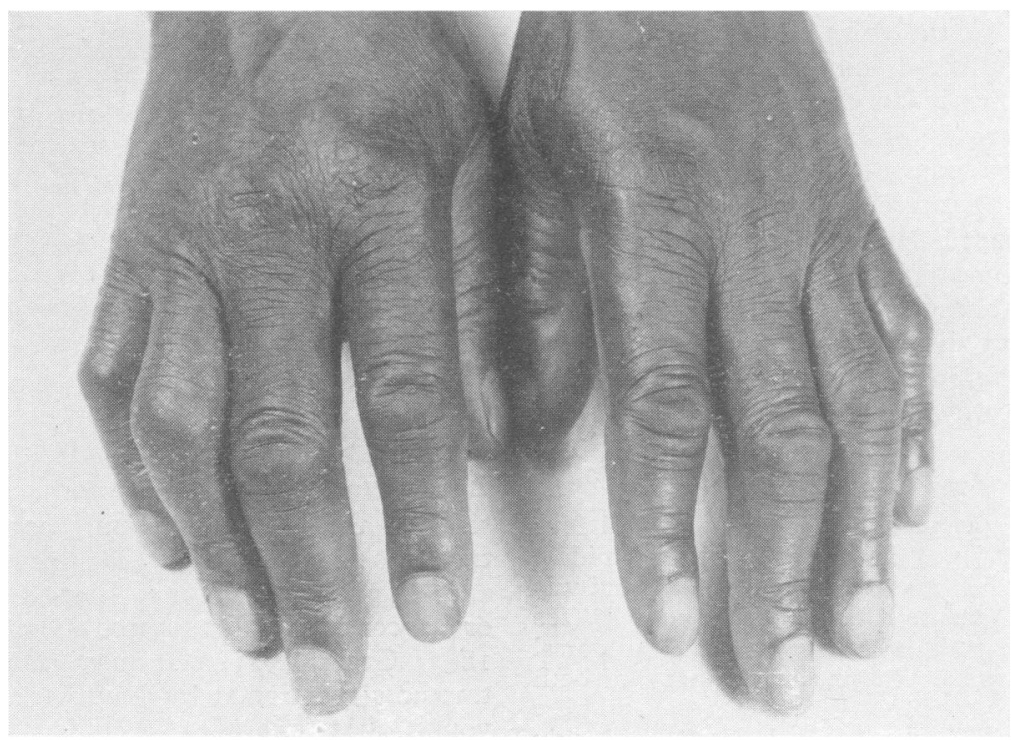

FIG. 3. Hands of proband III.2. Note the knuckle pads over the proximal interphalangeal joints of the index and middle fingers, and (R) ring finger, obliterating or displacing the normal dorsal joint creases. 
TABLE

ANALYSIS OF REPORTED CASES OF CAMPTODACTYLY

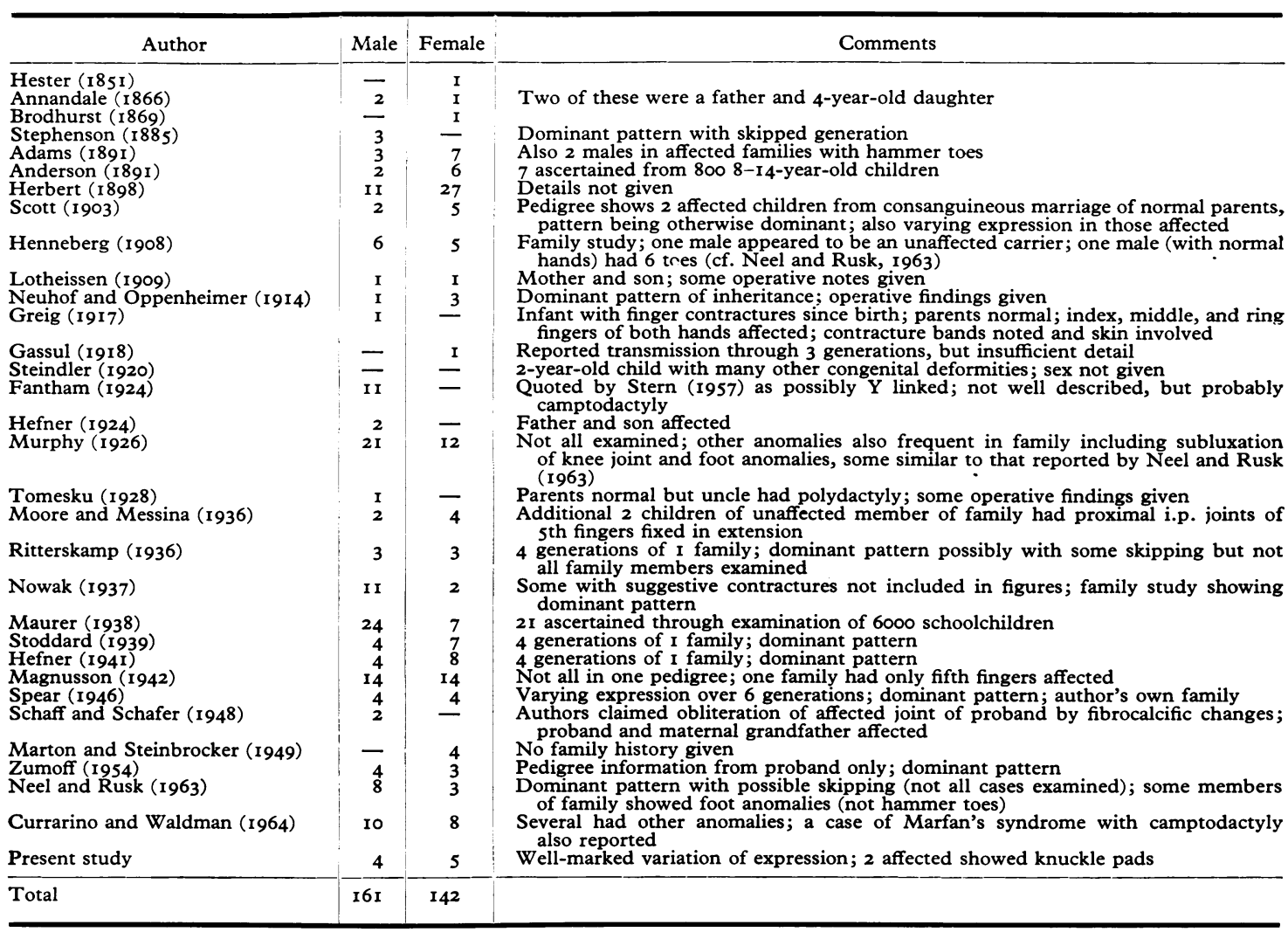

Not included in this Table, because of insufficient information, are 3 pedigrees given by Allan (1939), which show a total of 5 females and 6 males affected Also excluded are the data of Goldflam-Warschau (1906), since almost all these cases were atypical in that only the distal i.p. joint was involved.

'streblomicrodactyly'. Confusion has been further compounded by Clarkson and Pelly (1962) who remarked that congenital contractures might affect any of the proximal interphalangeal joints and that when it occurred in the fifth finger, it was known as 'campylodactyly'.

Camptodactyly should be distinguished from clinodactyly (brachymesophalangy of the fifth finger), the latter referring to a radial curvature of the little finger, which is often associated with a triangular appearance of the middle phalanx, and which is a frequent finding in many unrelated syndromes, such as Down's syndrome (mongolism) and the oro-facio-digital syndrome. Clinodactyly may also occur as an isolated finding, inherited as a dominant trait, and is regarded by Bell (I95I) as a type of brachydactyly (type A3). Some authors have confused clinodactyly with campto- dactyly, sometimes grouping the two together as 'crooked little fingers' (e.g. Gates, 1946).

It is suggested that the original term camptodactyly should be applied to all cases fitting the given description, no matter which finger is affected.

Incidence. Most authors who mention the condition comment that it is more frequent in girls, and this is commonly given as a point of differentiation from Dupuytren's contracture. A survey of the past literature was made in an attempt to get a more accurate impression of the sex incidence. Results are given in the Table. While these are hardly a random or unbiased sample, they do represent all the reported cases that are likely examples of the condition. Clearly, on these 
figures, the condition is equally distributed between the sexes. It may be noted that the cases reported by Goldflam-Warschau (1906) do not fit into the usual pattern, since, in his cases, the distal interphalangeal joint was principally affected. In regard to the over-all frequency, a rough indication is gained from the work of Anderson (189I) who found 7 cases among 800 schoolchildren, and Maurer (1938) who found 21 cases among 6,000 schoolchildren. Sorrel (I938) reported a case of 'camptodactyly' of the thumb (bilateral), but in this case the condition was due to a tendon abnormality (presence of nodules demonstrated at operation) indicating that this was almost certainly not the same condition as that under discussion.

It is of some historical interest that the suggestion has been made that the model used by Dürer in his famous painting of hands in prayer, was possibly a sufferer from early Dupuytren's contracture; examination of the painting seems to indicate, however, that the owner of the hands, if he had any abnormality, more probably had camptodactyly.

Pathology. The nature of the deformity is not well known, most of those affected being little inconvenienced, so that few cases come to operation and subsequent pathological examination. This has given rise to much speculation as to the nature of the deformity, usually on scant evidence. Scott (1903) and also Magnusson (1942) believed that the deformity was due to a volar tilting of the heads of the proximal phalanges, but this is not substantiated even by their own radiographs. Others have claimed that there is a subluxation at the affected joint but, as has been pointed out most recently by Hueston (1963), when the normal joint is flexed the second phalanx rides down on to the neck of the first phalanx. Greig (1917) and Hefner (1924) believed that the condition was due to contraction of the long or short flexors: however, examination with wrist flexion readily rules out this possibility. It has also been suggested that the condition is due to contracture of the lateral ligaments of the first interphalangeal joint. This is largely based on the report of Neuhof and Oppenheimer (1914) who found it necessary to divide the lateral ligaments in order to bring about extension. However, they also found, and divided, a firm band of fascia over the flexor tendons, and their own conclusion was that the condition was brought about by the 'contracted condition of the skin and fascia and partly by the contracted condition of the articular ligaments by adopted shortening during growth' (our italics).
It should be noted that similar shortening of collateral ligaments may also be found in sever Dupuytren's contracture (Hueston, I963). If camptodactyly were similar to Dupuytren's con tracture, it would be expected that the collater ligaments would be secondarily involved mores often in the former condition, since finger contraç tures commonly arise during the growing period whereas Dupuytren's (i.e. with palmar changes usually arises only in adult life.

The operative finding of contracted fascia bands, spanning the volar surface of the joint and thus giving rise to the condition, was notesp by Jobert and Blandin as long ago as 1846 and subsequently by Adams (I89I), Nichols (I89g\% Lotheissen (1909), Tomesku (1928), and Cufu rarino and Waldman (1964). Perhaps the most interesting account was that of Lockwood (I88Q who described the dissection of two cases and comopared them with a typical Dupuytren's contracture according to Lockwood, the bands were adherent to skin, and in a case where the whole hand wass available, the fascial bands extended far into the palm. The only distinction from Dupuytrenof contracture lay in the greater implication of skin and palmar fascia in the latter. One of the fingef contracture specimens was placed in the SE. Bartholomew's Hospital Museum (No. 1203 Bळ Certain other authors, notably Schultze (1913) have also commented on the similarity to Dupugs tren's contracture.

A search of records at the Johns Hopkins Hos? pital disclosed a case which appeared consistem with the theory regarding the relative importanu․․ of the role played by the contracted subcutaneous tissue. This was a 4-year-old white male (K. $\vec{b}$ 670983) in whom camptodactyly of the left little finger had been noted from birth. At operation only the lateral joint ligaments were divided and the finger was forcibly extended. Extension was ne retained after operation, and examination now clearly reveals contracture bands spanning the volar surface of the joint. Clinical examination w otherwise normal and there was no history of an other affected member of the family.

Nichols (1899) described a typical case of corf tracture of a single digit at the proximal intę phalangeal joint and though admitting that the contracture of the digital fascia is analogous the 'common' type of Dupuytren's contracturE, he did not feel he could classify it as such. He alsị claimed to have seen cases of 'hammer fingen' arising in adult life and two cases of 'hammer finger' associated with Dupuytren's contractufe (presumably palmar) which he was unable to classifo. 
More recently, Hueston (1963), while remarking that typical Dupuytren's contracture may arise at an early age (e.g. in a 12-year-old male observed by him), added that it should not be confused with 'hypoplasia of the volar digital structures, commonly symmetrical, in little girls (campylodactylia)'. However, he goes on to comment that Dupuytren's may occasionally manifest as a short interphalangeal band producing a flexion deformity of the proximal interphalangeal joint. This band was described in some detail and a photograph showed an affected fourth digit with hyperextension at the metacarpophalangeal joint typical of the 'congenital' contracture.

It seems reasonable to conclude that Dupuytren's contracture and camptodactyly, though genetically distinct, may be related disease processes with occasional phenotypic overlap.

Associated Conditions. It is now recognized that Dupuytren's contracture is not uncommonly associated with other connective tissue anomalies, such as plantar nodules (Conway, 1954) and with Peyronie's syndrome (Skoog, 1948; Hueston, 1963) of which, a familial instance has recently been reported (Murley, 1964). There also seems to be some association with epilepsy, though its nature is not clear (Lund, 194I ; Skoog, I948; Early, 1962).

The best documented association, however, is that with knuckle pads (Garrod, 1893, 1904; White, I908; Lund, 194I; Weber, 1938; Skoog, I948), the association being so close that it has been asserted that those who show this feature always either have, or later develop, Dupuytren's contracture (McIndoe and Beare, 1958). The findings in the family here reported, however, indicate that knuckle pads may also occur with camptodactyly, the two affected members being of such an age that a 'typical' Dupuytren's contracture would probably have appeared, were it going to develop. Futhermore, we have since seen knuckle pads in an affected member of another family with camptodactyly, while a photograph in another recent publication (Barinka, 1964a, photograph ra) also suggests the coexistence of knuckle pads. It is of historical interest that Garrod (I904), commenting on the occurrence of Dupuytren's contracture in those with knuckle pads, remarked that, 'in most instances the puckering in the palm was well marked ... . but in one or two there was merely a fibrous thickening on the palmar aspect of the little finger, causing flexion, but without any obvious implication of the palmar fascia'. These observations on knuckle pads appear to lend substance to the theory of phenotypic overlap between camptodactyly and Dupuytren's contracture.

There are a few reports of coexistent camptodactyly and Dupuytren's contracture (Nichols, 1899; Weber, 1938; Barinka, 1964b), and Skoog (1948) noted a Dupuytren's contracture in a 74-year-old woman who had had bilateral 'hammer toes' since youth (the latter not infrequently found in families and individuals with camptodactyly (Adams, I891, 1892; Koenner, 1934; Barinka, I964b)). These may represent a phenotypic overlap, but could be simply chance, since Dupuytren's contracture is exceedingly common in later life, possibly as high as $15-20 \%$ (Early, 1962, 1964), at which time the sex incidence may approach equality (Hueston, 1963).

It is now apparent that a number of conditions may be associated with camptodactyly. Foot anomalies other than hammer toes may be found, the most striking being a bony outgrowth of the second metatarsal which may be surmounted by one, or possibly more, extra phalanges. Externally it may be marked by a curious overlapping of the second and third toes. We have noted this in one female member of a family with camptodactyly (Fig. 4 and 5) who also had fusion of the first and second cuneiform bones. The mother and other members of the family had camptodactyly, but no other abnormalities were detected nor was there any known consanguinity. Neel and Rusk (1963) have also described these features among some members of a family with camptodactyly, though they considered it a separate entity from camptodactyly. Barinka (1964b) has published photographs of patients with camptodactyly, which are strongly reminiscent of this foot anomaly, and Murphy (1926) may well have been describing the same condition. Henneberg (1908) reported polydactyly of the toes (type unspecified) in a family with camptodactyly. A solitary report (Tomesku, 1928) which mentions polydactyly of the fingers in an uncle of a patient with camptodactyly is probably not pertinent.

In other instances camptodactyly appears to be part of the pleiotropic clinical spectrum of certain genetically determined conditions which otherwise show little phenotypic overlap with each other. Thus it is well known that camptodactyly is not infrequent in Marfan's syndrome, a genetically determined, dominantly transmitted, generalized connective tissue disorder (Marfan, 1896; Kallius, 1928; McKusick, I960).

In another disorder, cranio-carpo-tarsal dystrophy, first described by Freeman and Sheldon (1938), severe camptodactyly is an almost constant 


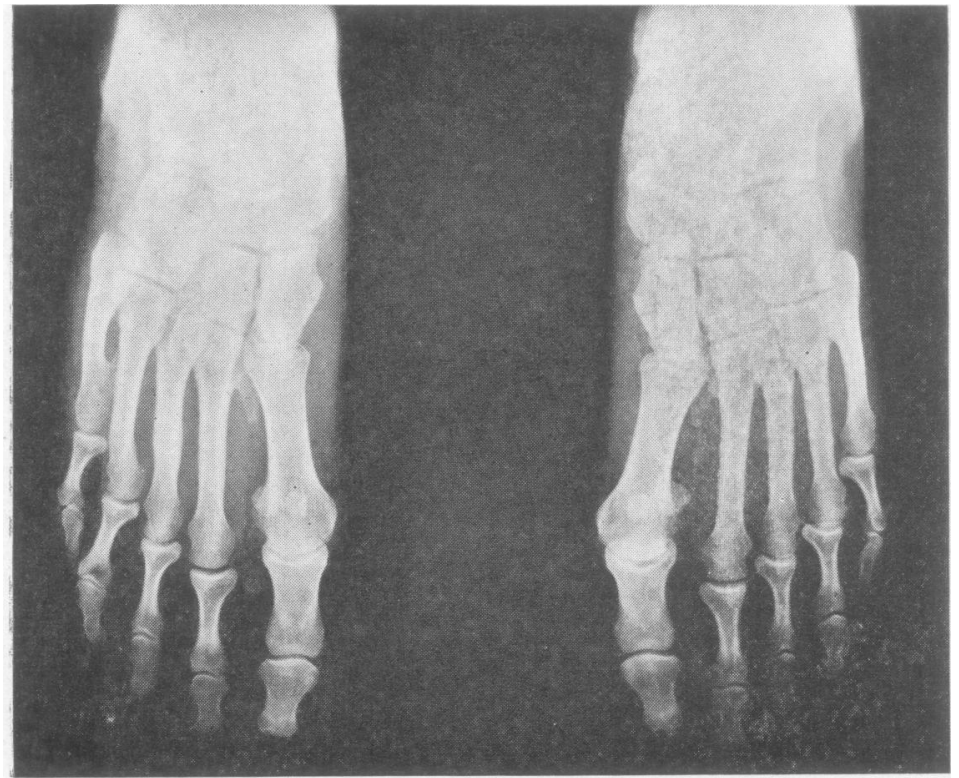

Fig. 5. Hands of the same patient as in Fig. 4, showing camptodactyly of the fifth fingers of both hands, more marked on the right. Note the 'band' on the palmar surface of the left fifth finger and the tight appearance of the skin around the distal phalanges of all the digits.

FIG. 4. Radiograph of feet showing bony spurs arising from the proximal portions of the second metatarsal bones. There is also a similar bony spur arising from the distal portion of the right fifth metatarsal with bilateral fusion of the first and second cuneiform bones and also of the middle and distal phalanges of the lateral four toes. Radiographs of other parts of the body reverled a slight thoracic scoliosis but no other skeletal abnormalities.

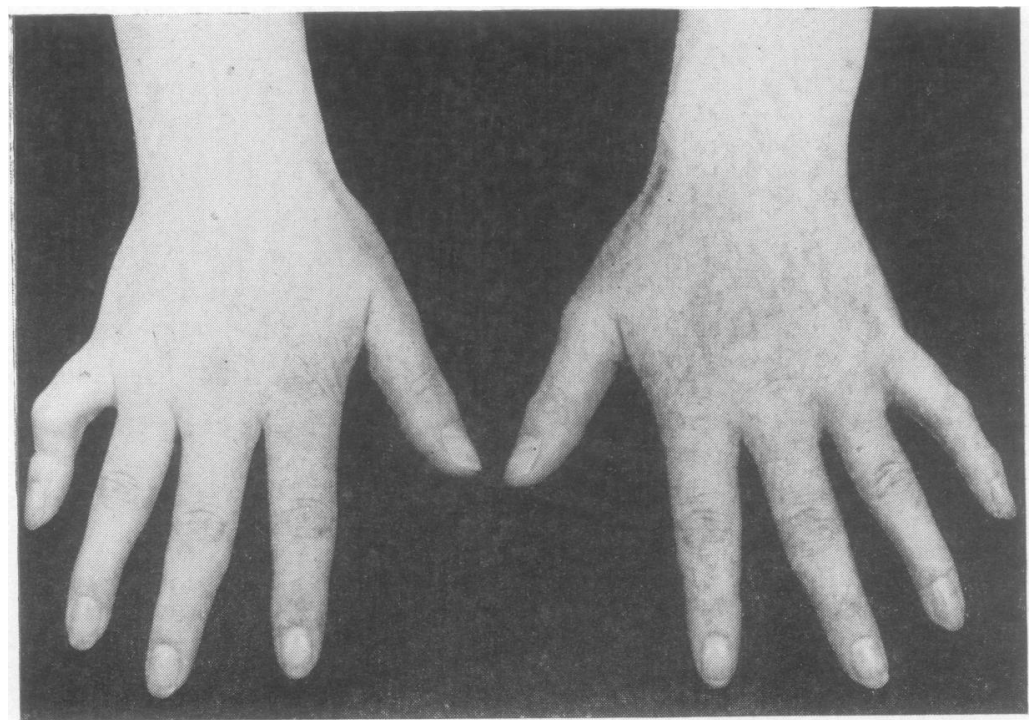


feature, and some familial occurrences suggest an autosomal dominant mode of inheritance.

Camptodactyly is also a frequent feature of a third syndrome, oculodento-digital dysplasia, for which the report of Gillespie (1964) of two affected sibs suggests an autosomal recessive mode of inheritance.

In addition to the above associations, there is evidence that camptodactyly may be a frequent accompaniment of a group of other anomalies. Thus Maurer (1938) described 3I cases of camptodactyly and found a high incidence of other abnormalities which he believed to be indicative of a particular 'constitutional type'. Prominent among his findings were funnel chest deformity (17/3r), slight 'winging' of the scapula (15/3I), and elevation of one or other scapula (7/3I). A large number were also claimed to show a high-arched palate; and kyphoscoliosis, ptosis, hemi-hypertrophy, and arachnodactyly were also reported in some cases. Barinka (1964a, b) has also noted the association with arachncdactyly, contractures of the toes and funnel sternum, and published photographs that appear to illustrate some of the other anomalies described by Maurer in patients with camptodactyly. Steindler (1920) reported the case of a 2-year-old child with probable camptodactyly, elevation of the left scapula, scoliosis, fusion of the third and fourth ribs on the left side, and possibly other ano nalies.

Hanley and McKusick (1966) described the occurrence of some of the features described by Maurer in 1938 (pectus excavatum and ptosis) in two strikingly similar brothers, one of whom had camptodactyly. Also noted in these sibs were hypertelorism, osteochondritis dissecans, maldescent of the testes, and, in one, hypogonadism.

Recently Currarino and Waldman (1964) reported I9 cases of camptodactyly. They noted the occurrence of ptosis in some patients and of partial hemi-hypertrophy in one patient. They also reported the occurrence of camptodactyly in a case of presumed Klinefelter's syndrome (chromosome studies not reported) which might be compared to the hypogonadal state noted in one of the two sibs described by Hanley and McKusick (I966).

The association of camptodactyly with pectus excavatum, slight thoracic scoliosis, dwarfism, and bilateral ptosis was also noted in a single female patient during a survey of hand anomalies being conducted by one of us (S.A.T.). The chest deformity is often marked by undue prominence of the manubrio-sternal junction (also shown in Maurer's photograph of a case) which in our own patient and in the sibs described by Hanley and McKusick (1966) appears attributable to premature fusion of this joint-an otherwise uncommon sternal malformation (Currarino and Silverman, 1958).

Aetiology and Conclusions. The aetiology of Dupuytren's contracture has long been a subject of discussion; however, there now seems little doubt that there is a strong genetic influence, the disease frequently being familial (Garrod, 1904; Sprogis, 1926; Schröder, 1934; Skoog, 1948; Ling, 196r, 1963). It is now recognized that Dupuytren's contracture is often bilateral (Davis and Finesilver, 1932) and may be associated with other disorders (see above).

Camptodactyly occurring as an isolated finding is also an inherited condition, the usual pattern of transmission being that of a dominant trait with a few instances of possible transmission through an unaffected individual (non-penetrance) (see Table). The family presented, and also that reported by Scott (1903), clearly demonstrate the variation in severity, and that camptodactyly of the little finger is not to be distinguished from that occurring in other digits.

Camptodactyly also forms part of the spectrum of at least three genetically determined conditions, namely, Marfan's syndrome, cranio-carpo-tarsal dystrophy, and oculo-dento-digital dysplasia. The possibility of a fourth, previously unrecognized, syndrome in which camptodactyly is one of the most constant features, is suggested by the observations of Maurer (1938), Hanley and McKusick (1965), by our findings outlined above, and by Cases 2 and 8 reported by Currarino and Waldman (1964). This syndrome frequently features pectus excavatum, mild scoliosis, ptosis, and hypogonadism. In some instances in which camptodactyly has occurred in conjunction with one or more of the above anomalies, additional features have been noted including dwarfism, winging or elevation of the scapula, high arched palate, and some degree of hemi-hypertrophy. (See Barinka, 1964b; Steindler, 1920.) The pattern of inheritance is most probably that of a dominant trait with variable penetrance.

It also seems well established that foot anomalies may occur in association with camptodactyly, though it is much less clear at this time whether the latter association is part and parcel of the supposed fourth syndrome described above. We have, however, seen a single case in which these foot anomalies were associated with radiological evidence of scoliosis (see Fig. 4). Alternatives are that the 
bony changes in the feet are occasionally associated with otherwise 'simple' camptodactyly, or that they constitute yet another distinct syndrome. A further possibility is that consanguinity may account for some of the cases with associated foot deformities, as suggested by the findings in one family that all the proven cases showing such features occurred in the offspring of consanguineous matings (Neel and Rusk, 1963).

It remains possible that all these manifestations simply reflect the variability, commonly associated with dominant traits, of a single entity, camptodactyly. We feel, however, that the occurrence of similarly severely affected individuals in some families, and apparently 'simple' camptodactyly in other families, argues for the existence of distinct entities.

Finally, the possibility of environmental influence in the determination of camptodactyly may be mentioned. Walters and Zahra (1957) found a greatly increased incidence of 'Dupuytren's contracture' among a few villages in Eastern Nigeria, which seemed significantly correlated with an increased incidence of yaws in that area, though a genetic explanation is probably not excluded. Their description of the condition closely resembles camptodactyly, possibly with knuckle pads in some cases, rather than the classical Dupuytren's contracture.

Further progress in our knowledge of the genetics of camptodactyly is most likely to come through examination of more persons showing this trait, and it should be emphasized that the occurrence of this condition should never be assumed to be a solitary anomaly. Furthermore, the family history should always be ascertained and preferably followed by examination of all relatives showing possible anomalies. It should be remembered that the person with camptodactyly may simply be exhibiting a mild expression of a deleterious genetic influence more obviously manifest in other members of his family.

\section{Summary}

A family showing hereditary contractures of the fingers (camptodactyly) is presented and discussed. The condition is frequently overlooked and its pathology poorly understood.

In this presentation and review an attempt has been made to suggest that many of the features enumerated in the past as providing points of differentiation of camptodactyly from Dupuytren's contracture are not valid; only the lack of involvement of the metacarpo-phalangeal joint, slower progression, absence of puckering of the skin with overt palmar involvement, and occurrence at ans early age, provide truly distinguishing features? when attention is limited to the changes in the hands.

It is also suggested that camptodactyly ande Dupuytren's contracture may each be simply facets of more generalized connective tissue disorders which show some phenotypic overlap, and that camptodactyly may be one of the pleio-n tropic manifestations of a number of genetically distinct disorders, as outlined, one of which has been recognized only relatively recently, and may $\vec{\omega}$ show pectus excavatum, scoliosis, ptosis, hypo gonadism, and other anomalies.

This work was supported in part by National Insti tutes of Health grant GMror89.

\section{REFERENCES}

Adams, W. (I89I). On congenital contraction of the fingers and it association with 'hammer toe'. Lancet, 2, I I I and 165.

(1892). On Contractions of the Fingers and on Hammer-toe, 2nd ed. J. and A. Churchill, London.

Allan, W. (1939). Inheritance of short finger tendons. f. Hered. ద 30, 218.

Anderson, W. (I89r). Contractions of the fingers and toes. Lancet 2, 107.

Annandale, T. (1866). The Malformations, Diseases and Injuries of the Fingers and Toes. Lippincott, Philadelphia.

Bailey, H. (1960). Demonstrations of Physical Signs in Clinica

Surgery, 13th ed. J. Wright, Bristol.
Barinka, L. (1964a). Campylodactylia. Acta Chir. plast. (Praha) $\frac{\mathrm{O}}{\mathrm{D}}$ 6, 54 .

(I964b). Notes on campylodactylia. II. ibid., 6, I 54.

Barsky, A. J. (1958). Congenital Anomalies of the Hand and their Surgical Treatment. Charles C. Thomas, Springfield, Illinois, Blackwell Scientific Publications, Oxford.

Bell, J. (195I). On brachydactyly and symphalangism, p. 5. (The Treasury of Human Inheritance. Vol. V. On Hereditary Digital Anomalies, ed. L. S. Penrose. Part I.) Cambridge University Press, London.

Boyes, J. H. (1964). Bunnell's Surgery of the Hand, 4th ed. Lippincott, Philadelphia.

Brodhurst, B. E. (1869). Lectures on orthopedic surgery. V. Or? contractions of the limbs. Lancet, $\mathbf{x}, 35$.

Clarkson, P., and Pelly, A. (1962). The General and Plastic Surgery of the Hand, p. 418. Blackwell, Oxford.

Conway, H. (I954). Dupuytren's contracture. Amer. F. Surg.0 87, ror.

Currarino, G., and Silverman, F. N. (1958). Premature obliteration $D$ of the sternal sutures and pigeon breast deformity. Radiology? 70, 532 . 92, 1312.

Davis, J. S., and Finesilver, E. M. (1932). Dupuytren's contraction N

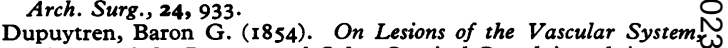
Diseases of the Rectum, and Other Surgical Complaints; being . . Clinical Lectures, translated and edited by F. Le Gros Clark Sydenham Soc., London.

Early, P. F. (1962). Population studies in Dupuytren's contracture f. Bone ft Surg., 44B, 602 .

(1964). Genetics of Dupuytren's contracture. Brit. med. $\mathcal{F} . \stackrel{\mathcal{E}}{+}$

Fantham, H. B. (1924). Heredity in man: its importance both biologically and educationally. $S . A f r . \mathcal{F}$. Sci., $21,500$.

Forrester-Brown, M. F. (1929). Diagnosis and Treatment of Defor mities in Infancy and Early Childhood. Oxford University Press $x$ Oxford. 
Freeman, E. A., and Sheldon, J. H. (1938). Cranio-carpo-tarsal dystrophy. An undescribed congenital malformation. Arch. Dis. Childh., 13, 277.

Garrod, A. E. (1893). On an unusual form of nodule upon the joints of the fingers. St Bart. Hosp. Rep., 29, 157.

- (1904). Concerning pads upon the finger joints and their clinical relationships. Brit. med. F., $2,8$.

Gassul, R. (1918). Eine durch Generationen prävalierende symmetrische Fingerkontraktur. Dtsch. med. Wschr., 44, I 196.

Gates, R. R. (1946). Human Genetics. Macmillan, New York.

Gillespie, F. D. (1964). A hereditary syndrome: 'dysplasia oculodentodigitalis'. Arch. Ophthal., 71, 187.

Goldflam-Warschau, S. (1906). Ein Fall von kongenitaler, familiärer Ankylose der Fingergelenke. Münch. med. Wschr., 53, 2299.

Greig, D. M. (1917). A case of congenital Dupuytren's contraction of the fingers. Edinb. med. F., 19, 384

Hanley, W. B., and McKusick, V. A. (1966). f. Bone ft Surg. To be published.

Hefner, R. A. (1924). Inherited abnormalities of the fingers. $\mathcal{f}$. Hered., 15, 481 .

- (1929). Inheritance of crooked little fingers (streblomicrodactyly). ibid., 20, 395 .

(194I). Crooked little fingers: (minor streblomicrodactyly). ibid., 32, 37.

Henneberg (1908). Kasuistischer Beitrag zur kongenitalen, familiären, dermatogenen Kontraktur der Fingergelenke. Dtsch. med. Wschr., 34, 1804

Herbert (1898). La camptodactylie. Gaz. hebd. Méd. Chir., n.s., 3, 771 .

Hester, J. T. (185I). On congenital contractions of the fingers. Med. Times (Lond.), n.s. 2 (o.s. 23), 315.

Hueston, J. T. (1963)、Dupuytren's Contracture. Livingstone, Edinburgh.

Jobert, and Blandin (1846). La rétraction des doigts par des brides accidentelles. Ann. de Therapie, Févre, p. 432.

Kallius, H. U. (1928). Ein Fall von Arachnodaktylie. Dtsch. $Z$. Chir., 209, 256.

Keen, W. W. (1882). The etiology and pathology of Dupuytren's contracture of the fingers. Philad. med. Times, 12, 370.

Koenner, D. M. (1934). Abnormalities of the hands and feet. F. Hered., 25, 329.

Ling, R. S. M. (1961). Genetic factor in Dupuytren's disease. Lancet, 2, 912 .

- (1963). The genetic factor in Dupuytren's disease. f. Bone ft Surg., 45B, 709.

Lockwood, C. B. (1886). Contractions of the digital and palmar fascia. Trans. path. Soc. Lond., 37, 556.

Lotheissen (1909). Discussion in Wien. klin. Wschr., 22, 216

Lucas-Championnière, P. (1885). Sur une deformation particulière des doigts propre à l'arthritisme. F. Méd. Chir. prat., 56, 485.

Lund, M. (I94I). Dupuytren's contracture and epilepsy. Acta psychiat. (Kbh.), 16, 465 .

McIndoe, A. H., and Beare, R. L. B. (1958). The surgical management of Dupuytren's contracture. Amer. F. Surg., 95, 197.

McKusick, V. A. (1960). Heritable Disorders of Connective Tissue, and ed. C.V. Mosby, St. Louis.

Magnusson, R. (1942). La camptodactylie. Acta chir. scand., 87, 236.

Marfan, A. B. (1896). Un cas de déformation congénitale des quatre membres plus prononcée aux extrémitiés caracterisée par l'allongement des os avec un certain degré d'amincissement. Bull. Soc. Méd. Paris, 13, 220.

Marton, R., and Steinbrocker, O. (1949). Congenital contracture of the fifth finger. N.Y. St. F. Med., 49, 1064.
Maurer, G. (1938). Die Kamptodaktylie. Arch.orthop. Unfall-Chir. 39, 365.

Moore, W. G., and Messina, P. (1936). Camptodactylism and its variable expression. F. Hered., 27, 27.

Murley, R. S. (1964). Peyronie's disease. Brit. med. F., 1, 908.

Murphy, D. P. (1926). Familial finger contracture and associated familial knee-joint subluxation. f. Amer. med. Ass., 86, 395.

Neel, J. V., and Rusk, M. L. (1963). Polydactyly of the second metatarsal with associated defects of the feet: a new, simply inherited, skeletal deformity. Amer. F. hum. Genet., 15, 288.

Neuhof, H., and Oppenheimer, E. D. (1914). Congenital contractures of the fingers, with the report of a case of the familial type. Surg. Gynec. Obstet., 19, 193.

Nichols, J. B. (1899). A clinical study of Dupuytren's contraction of the palmar and digital fascia. Amer. F. med. Sci., 117, 285.

Nowak, H. (1937). Die familiäre Ankylose der Fingergelenke. Dtsch. med. Wschr., 24, 937.

Ritterskamp, P. (1936). Eine Familie mit Kamptodaktylie. Münch. med. Wschr., 83, 724 .

Schaff, B., and Schafer, P. W. (1948). Camptodactyly. Arch. Surg., 57, 633 .

Schröder, C. H. (1934). Der Erbgang der Dupuytren'schen Kontraktur. Zbl. Chir., 61, 1056.

Schultze, E. (1913). Angeborene familiäre Kontraktur der Gelenke des kleinen Fingers. Z Zbl. GrGeb. Med. Chir., 16, 608.

Scott, J. (1903). Hammer-finger, with notes of seven cases occurring in one family. Glasg. med. 7 ., 60, 335 .

Skoog, T. (1948). Dupuytren's contraction. Acta chir. scand., 96, Suppl. 139 .

Sorrel, E. (1938). Un cas de camptodactylie des deux pouces. Mém. Acad. Chir., 64, 628.

Souttar, Sir H. S., and Goligher, J. C. (1958). Textbook of British Surgery, Vol. III. Heinemann, London.

Spear, G. S. (1946). The inheritance of flexed fingers. F. Hered., 37, 189 .

Sprogis, G. (1926). Beitrag zur Lehre von der Vererbung der Dupuytrenschen Fingerkontraktur. Dtsch. Z. Chir., 194, 259.

Steindler, A. (1920). Congenital malformations and deformities of the hand. F. orthop. Surg., 2, 639.

Stephenson, S. H. A. (1885). Hereditary transmission of Dupuytren's contraction. Brit. med. F., I, 536 .

Stern, C. (1957). The problem of complete $\mathrm{Y}$-linkage in man. Amer. F. hum. Genet., 9, 147.

Stoddard, S. E. (1939). Nomenclature of hereditary crooked fingers: Streblomicrodactyly and camptodactyly-are they synonyms? f. Hered., 30, $5 \mathrm{I} I$.

Tamplin, R. W. (1846). Lectures on the Nature and Treatment of Deformities. Barrington and Haswell, Philadelphia.

Tomesku, I. (1928). Kongenitale deviationen der Phalangen. Arch. orthop. Unfall-Chir., 26, 126.

Walters, J. H., and Zahra, A. (1957). The aetiology of Dupuytren's contracture in Eastern Nigeria. Trans. roy. Soc. trop. Med. Hyg., 51, 346.

Weber, F. P. (1938). A note on Dupuytren's contraction, camptodactylia and knuckle pads. Brit. F. Derm., 50, 26.

White, W. H. (1908). On pads on the finger-joints. Quart. F. Med., I, 479.

Whitman, R. (1930). A Treatise on Orthopedic Surgery, 9th ed. Lea \& Febiger, Philadelphia.

Zumoff, B. (1954). Congenital symmetrical finger contractures. f. Amer. med. Ass., 155, 437. 